\title{
A SUPPORTING HAND IN DEALING WITH INTERPERSONAL CONFLICTS: THE ROLE OF INTERACTIONAL JUSTICE
}

\author{
Nurul Ain Hidayah Abas ${ }^{1 *}$, Kathleen Otto², and Ramayah Thurasamy ${ }^{3,4}$ \\ ${ }^{1}$ Department of Psychology and Counselling, Universiti Pendidikan Sultan Idris, \\ 35900 Tanjung Malim, Perak, Malaysia \\ ${ }^{2}$ Faculty of Psychology, Philipps University of Marburg, 35037 Marburg, Germany \\ ${ }^{3}$ School of Management, Universiti Sains Malaysia, 11800 USM Pulau Pinang, Malaysia \\ ${ }^{4}$ Visiting Professor at Faculty of Cognitive Science and Human Development, \\ Universiti Malaysia Sarawak, 94300 Kota Samarahan, Sarawak, Malaysia \\ *Corresponding author: nurulain@fpm.upsi.edu.my
}

Published online: 29 June 2018

To cite this article: Abas, N.A.H., Otto, K., and Ramayah, T. (2018). A supporting hand in dealing with interpersonal conflicts: The role of interactional justice. Asian Academy of Management Journal, 23(1), 79-99. https://doi.org/10.21315/aamj2018.23.1.4

To link to this article: https://doi.org/10.21315/aamj2018.23.1.4

\begin{abstract}
Studying the styles in managing conflicts is critical in preventing the detrimental effects of interpersonal conflicts on employees' well-being. In a sample of 390 Malaysian public sector subordinates, the relationships between conflict management styles (bargaining and problem solving) and psychological strain (somatic strain and depressive symptoms) was explored. Based on social exchange theory, it was further expected interactional justice to work as a moderator in this relationship, buffering the negative consequences of bargaining styles for subordinates with supervisors whom are having high rather than low interactional justice. Results indicate that bargaining was positively associated with somatic strain, while problem-solving was negatively associated with both somatic strain and depressive symptoms. As hypothesised, the PLS-SEM product moderator indicator approach analysis revealed that perceived interactional justice buffered the negative consequences of bargaining styles on somatic strain and depressive symptoms. This study's primary novelty is to highlight interactional justice as a "helping hand" protecting against the negative consequences of bargaining styles among subordinates. Consequently, it has a main practical implication for organisational management aimed at sustaining the wellbeing for their manpower.
\end{abstract}

Keywords: conflict management styles, depression, justice, strain, well-being

(C) Asian Academy of Management and Penerbit Universiti Sains Malaysia, 2018. This work is licensed under the terms of the Creative Commons Attribution (CC BY) (http://creativecommons. org/licenses/by/4.0/). 


\section{INTRODUCTION}

Interpersonal conflict is classified as one of the most prominent work-related stressors with respect to its influence on social interaction, personal relationships, satisfaction, and quality of work relationships (Spector \& Bruk-Lee, 2008). Given that some degree of interaction among organisational members is required in most workplaces, conflict is inevitable and consequently, has substantial implications for employees' well-being (e.g., Bono, McCullough, \& Root, 2008; Bruk-Lee \& Spector, 2006; Rahim, 2010). It might not be a conflict per se that is detrimental to health, but the way in which that particular conflict is resolved. Deciding on appropriate styles of managing conflicts with supervisors requires specific knowledge of its key antecedents from subordinates' perspective (Rahim, 2010).

Rahim and Bonoma (1979) developed The Dual-Concerns Model theory aimed at managing interpersonal conflicts with supervisors, subordinates, or colleagues. The model has its importance on concern for self and concern for others that promises a higher level of performance, better and quality decisions, and greater satisfaction of the both parties in an attempt to minimise the potential negative consequences to employees' organisational performance and well-being at the work place (Rahim, 2010). It has five styles in managing conflicts namely integrating, obliging, dominating, avoiding, and compromising that have been explored extensively. Although abundant research on conflict management and its effects on productivity are well conducted, far less attention has been devoted to "soft" outcomes, i.e., individual health and well-being (De Dreu \& Beersma, 2005). Hence, the present research would like to investigate the relationships between conflict management styles used when managing conflicts with one's supervisor with psychological strain, operationalised by somatic strain and depressive symptoms.

Next, conceding that potentially negative associations develop from applying a particular style, the question arises of which kinds of psychological resources provided in the work context can assist in sustaining subordinates' well-being. One possibility is supervisory support, reflected by subordinates' perceived quality of interpersonal treatment by their supervisors (Judge \& Colquitt, 2004). Coined as interactional justice, this dimension is more personal in nature and more closely associated with reactions and responses toward one's supervisor (Cropanzano, Prehar, \& Chen, 2002). Drawing on social exchange theory, we therefore argue that the relationships between subordinates' conflict management styles and psychological strain would be moderated by perceived interactional justice of supervisors. Subsequently, this study aims to contribute to the understanding of interactional justice in extending the theoretical grounding of justice-related effects on the domain of conflict management. 


\section{LITERATURE REVIEW AND RESEARCH HYPOTHESES}

\section{Conflict Management Styles: Bargaining and Problem Solving Dimensions}

The five conflict management styles can be organised into two dimensions: "integrative" which is a concern for self lies on a continuum of integrating avoiding; and "distributive" which is a concern for others that lies on a continuum of dominating - obliging following the labour management relations introduced by Walton and McKersie in 1965 (Figure 1). Rahim (2010) further explained that these two dimensions represent the "problem solving" and "bargaining" styles for managing interpersonal conflicts, respectively. A problem solving style refers to the degree high or low to which a party's attempt of own and others' concerns, while the bargaining style refers to the degree high or low to which a party's pursuit of own or others' concerns.

\section{CONCERN FOR SELF}

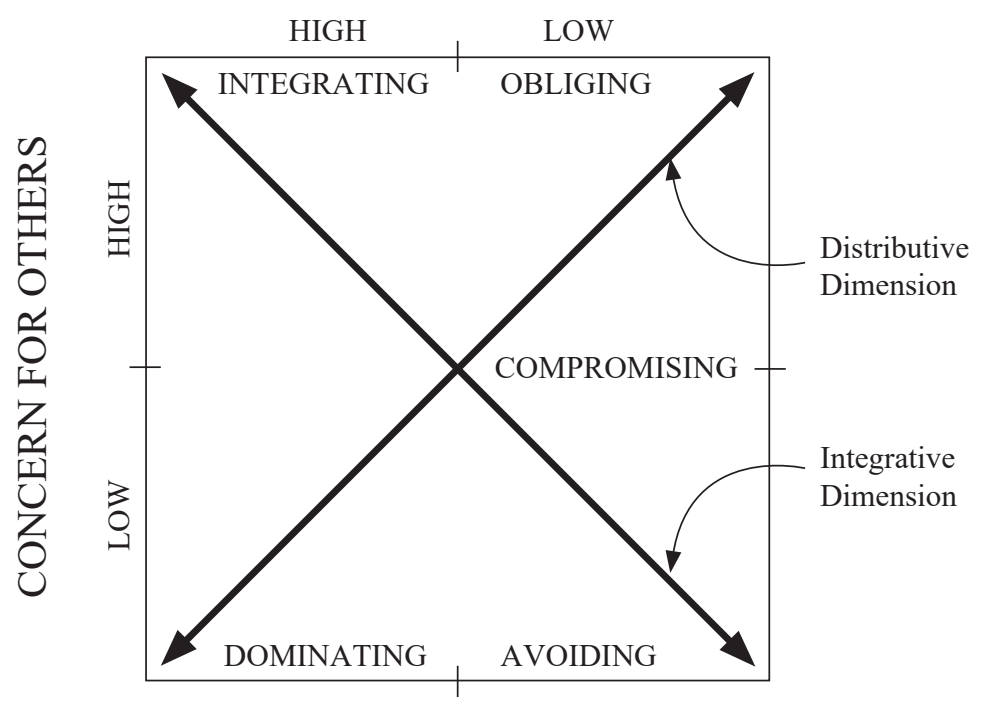

Figure 1. The Dual Concern Model: Problem solving and bargaining strategies for managing interpersonal conflict; from "a structural equations model of leader power, subordinates' styles of handling conflict, and job performance" (Rahim, Antonioni, \& Psenicka, 2001, p. 196).

For problem solving, a "high-high" is a high degree of a party's attempt of own concerns and others, indicating a concern for the satisfaction of both parties by finding acceptable solutions. In this case, the individuals take responsibility for 
their own actions and decisions, thus enhancing interpersonal relations, boosting feelings of self-worth and self-efficacy, and probably alleviating emotional strains as well. This is referred as a form of active (rather than passive) problem solving style. On the other hand, a "low-low" is a low degree of a party's attempt of own concerns and others. For example, a reduction of concern for both parties resulting from failure in confronting and resolving the issues at hand.

For bargaining, a "high-low" is a high degree of a party's attempt of own concerns and low to others, hence representing the attempt to satisfy one's concern with no or low concern for others, for example achieving decision without taking other party's consideration into account. Meanwhile a "low-high" is a low degree of a party's attempt of own concerns and high to others. It is an attempt to satisfy the opposite party by complying the needs with little or no concern of him/herself. Compromising, at the middle of these two dimensions, represents a moderate concern for the position of one's self and others. When a problem solving strategy cannot be used, the parties may decide to use a bargaining or win-lose style to resolve the conflict. Conflicts using bargaining may result in a feeling of victory or defeat, which may affect their psychological strain.

\section{The Role of Bargaining vs. Problem-Solving for Subordinates' Psychological Strain}

Interpersonal conflicts that are not managed appropriately could lead to both impaired cognition and affect as subordinates seek and react to negative events. They may experience stomach pain, headache, increase of heart palpitations, and muscle strain, called somatic strain as the body attempts to deal with the conflict (Claire, 2016).

In the same line, employees who are not clinically depressed reveal a variance in depressive symptoms that is strongly related to job satisfaction, depressive moods, and somatic complaints (Meier, Semmer, \& Gross, 2014). Depending on how subordinates manage their interpersonal conflicts, they can amplify, or dissolve emerging conflicts, while shaping the work environment to be supportive or destructive for themselves. Over time, this can mutually affect their cognitions and emotions, and in turn their psychological strains.

Relating with conflict management styles, it is argued that bargaining is positively associated with psychological strain. First, it is harder to reach an agreement in a dispute when one party only considers his or her own interests. Bringing the social psychology in, individuals who are proself-oriented are more concerned with personal outcomes and less concerned with the well-beings of others. Hence, 
these individuals are associated with bargaining style because of its social value preference (Schutz, 2015). As a consequence, these individuals are expected to have low interpersonal skills due to their inability to cooperate with others while managing conflicts which in turn may lead to isolation from other organisational members. As a result, it may cause negative emotions, resulting in symptoms of depressions as their need for affiliation is diminished.

Second, if subordinates prefer high bargaining in managing conflicts, their career may be jeopardised. This study argues that regardless supervisors' styles in managing conflicts, when a subordinate uses a high bargaining style with the supervisor, the subordinate needs to deal with a rival that not only has different interests, but also possesses a legitimate power over the subordinate's career (Frone, 2000). If the subordinate persists in using bargaining style, it may lead to more negative affect and emotions from the incongruent role and the struggle to satisfy the interests mutually acceptable to both parties. Therefore, it is predicted that:

H1: Bargaining in supervisory conflict will be positively related to somatic strain.

$\mathrm{H} 2$ : Bargaining in supervisory conflict will be positively related to depressive symptoms.

For problem solving style, it is predicted that it would be negatively related to psychological strain. Major theoretical and empirical studies have consistently shown that problem solving is the most effective conflict management style in resolving conflict in social interactions (e.g., Rahim, 2010). Supported by Friedman, Tidd, Currall, and Tsai (2000) it has been shown that those who are more integrating produce an environment with less conflict, and in turn, reduce their likelihood of experiencing stress.

In fact, people who use problem solving are able to adapt to their dispute resolution style, as explained by the prosocial orientation of the social value orientation (Schutz, 2015). Moreover, the effective problem solving was shown to buffer the depressive symptoms on subordinates' job satisfaction (Abas, Otto, \& Thurasamy, 2015). Worse, studies from Quiñones, Jurska, Fener, and Miranda (2015) found that people who use passive problem solving styles, rather than active, were among the highest contributors to suicide attempts. Therefore, it is plausible to assume that subordinates who use problem solving will be less likely to report psychological strain. It is then hypothesised: 
H3: Problem solving in supervisory conflict will be negatively related to somatic strain.

H4: Problem solving in supervisory conflict will be negatively related to depressive symptoms.

\section{Interactional Justice as a Buffer}

Interactional justice is a supervisory-focused dimension that is closely associated with the exchanging of relationships with one's supervisors (Cohen-Charash \& Spector, 2001). Past literature showed subordinates that perceived higher interactional justice from supervisors are more responsible for the subordinates' communications and actions, are more empathetic towards their needs, and show more respect towards themselves (Cohen-Charash \& Spector, 2001; Patient \& Skarlicki, 2010). Moreover, Elovainio, Kivimäki, and Vahtera (2002) also found that perceived interactional justice is less associated with employees' poor selfrated health and minor psychotic disorders.

From the aforementioned studies, it is argued that the negative consequences of bargaining styles on psychological strain can be buffered by perceived supervisors' interactional justice. Social exchange theory (Blau, 1964), defined as the reciprocal or exchange of tangible and/or intangible activities with social interaction or human behaviour for rewards or costs, was used as the backbone to explain this assumption. When conflicts are handled with bargaining styles, both parties may not be satisfied with the outcomes when only one party's concern is complied. These dissatisfactions from the negative emotions and cognitive impairment from the work stressor may be reduced in the form of social support (Kawakami, Kobayashi, Takao, \& Tsutsumi, 2005). As this study deals with interpersonal conflicts with supervisors, supervisory support is seen as essential to buffer the bargaining styles' negative consequences on psychological strain.

On the other hand, when supervisors are polite, kind, and show respect and dignity towards their subordinates, the supervisors are conveying messages that those subordinates involved and affected by the conflict are significant and worthy in their respect. The high quality relationship that is built with their supervisors, these subordinates who are proself-oriented (rather than prosocial) are able to sustain and nurture this mutual social relationship and consequently create a positive working environment for the supervisors and themselves. This reciprocal cycle will ultimately help in preventing psychological strain among subordinates. Thus, it is proposed: 
H5: Interactional justice moderates the positive relationship between bargaining and somatic strain in such a way that the relationship will be weakened when interactional justice is high, and the relationship will be strengthened when interactional justice is low.

H6: Interactional justice moderates the positive relationship between bargaining and depressive symptoms in such a way that the relationship will be weakened when interactional justice is high, and the relationship will be strengthened when interactional justice is low.

However, for a win-win problem solving style, their advantages in adopting their rivals' approach in conflicts, (Schutz, 2015) it may be reasonable to expect that their supervisors' interactional justice level does not make any significant contribution to their somatic strain or depressive symptoms. Nevertheless, in the interest of additional information, the justice moderation effect on problem solving-psychological strain will still be analysed.

\section{METHODS}

\section{Data Collection}

A total of 410 Malaysian employees from public sector organisations participated between August and December 2013 in a cross-sectional questionnaire-based study. In all survey interactions, each organisation was sent an introduction letter summarising the research and also a consent form which proved the authenticity of the study and confirmed anonymity. In order to increase response rate and convenience, questionnaires were available online and in printed format. Of the total number of surveys, 20 were excluded because of extensive missing data (more than $50 \%$ ). Finally, 390 surveys were analysed and used for hypotheses testing.

Of all the participants, $62.1 \%$ were female. Thirty per cent of the individuals held a bachelor's degree, whilst the remaining ranged from secondary school education to doctoral degree holders. The mean age was 34 years old $(\mathrm{SD}=8.42)$. Overall, $28 \%$ of the subordinates worked in general management, $24 \%$ in the field of finance and administration, $22.2 \%$ in human resources, $11.7 \%$ in customer service, $8 \%$ in the field of information technology, $3.3 \%$ in research and development (education), $0.8 \%$ in transportation, and both product support and marketing are $0.3 \%$ respectively. Their tenure with the supervisor ranged from less than a year to more than 30 years $(\mathrm{M}=4.54 ; \mathrm{SD}=16.59)$. 


\section{Measures}

The questionnaire comprised of multi-item measures with favourable psychometric properties. As some of these measures were not available in Malay, translation was mandatory using the following procedure (McGorry, 2000). A pre-test was conducted to examine the face validity of the instruments with three subjects that were experts in the specific problem domain. Three language experts (in Malay and English) and two decentering process experts were recruited to assist in the back translation procedure. The subjects' advice on improving the instruments' contents, design perspectives, and linguistics were considered in order to obtain a better quality translation. Subsequently, in a pilot study, a total of 123 subordinates voluntarily completed an online questionnaire to test the adequacy of the translated surveys to avoid potentially disastrous consequences of embarking on the main study, and to assess the time and resource problems that could occur. Upon response from the pilot study, minor alterations were made to the instruments.

\section{Conflict management styles}

Conflict management styles with a supervisor - integrating, avoiding, dominating, and obliging - were measured with 24 of the 28 reflective items of the Rahim Organizational Conflict Inventory-II (ROCI-II) ${ }^{1}$ Form A (Rahim, 2010). As aforementioned, four items were not included as they are measuring compromising styles that are not the interest of the main study. The respondents had to indicate the degree to which they dis(agreed) with each of the statements on a 5-point scale, with $1=$ strongly disagree and $5=$ strongly agree. A higher score indicates a higher use of that respective style with a supervisor. As suggested by Rahim (2010), scores from ROCI-II were constructed into the following two dimensions:

1. Problem solving style $(\mathrm{PB})=$ Integrating style - Avoiding style

2. Bargaining style $(\mathrm{BG})=$ Dominating style - Obliging style

Subscales for both dimensions of problem solving and bargaining style are ranged between +4 and -4 . For the problem solving subscale, +4 represents a person's attempt to provide high concerns for both parties, whereas a -4 score represents a person's attempt to provide no or low concerns for both parties. In the bargaining subscale, +4 indicates a person's attempt to provide high concern for self, while no or low concern for others. A -4 value indicates a person's attempt to provide no or low concern for self, and high for others. 


\section{Interactional justice}

Interactional justice (IJ) was measured using Colquitt (2001) and consisted of two facets: interpersonal and informational justice. Both measures are anchored by $1=$ rarely and $5=$ very often, on a 5 -point Likert scale. An example of interpersonal items is "Has your supervisor treated you in a polite manner?" and for informational item is "Does your supervisor communicate details in a timely manner?" One of the nine items, $I J 4$, i.e., "Has your supervisor refrained from improper remarks or comments" was excluded because of the low loadings suggested by Henseler, Ringle, and Sinkovics (2009).

\section{Somatic strain}

Pejtersen, Søndergård Kristensen, Borg, and Bjorner's (2010) Copenhagen Psychosocial Questionnaire (COPSOQ-II) was used to assess somatic strain (SM). The measure asks the respondent the degree to which an employee has experienced somatic strain in the workplace during the last four weeks. One of the four somatic strain items is "How often have you had tension in various muscles?" which was presented with a 5 -point scale ranged from $1=$ not at all to $5=$ all the time.

\section{Depressive symptom}

Depressive symptoms (DS), referring to the individual's life in general, were measured using 12 items from Bech, Rasmussen, Olsen, Noerholm, and Abildgaard's (2001) Major Depression Inventory (MDI). Functionally, the MDI consisted of 10 items. However, item 8 and item 10 both have two sub-items; $a$ and $b$, respectively. Only the highest score of either $a$ or $b$ for both items 8 and 10 will be counted, thus making it a total of 12 items. This measure used a 6-point Likert-scale ranging from $0=$ at no time to $5=$ all the time. A sample item reads, "How much of the time you have felt low or sad." The respondents had to answer based on what they had felt over the past two weeks.

\section{Data Analysis Strategy}

SmartPLS (Ringle, Wende, \& Will, 2005) was applied to empirically test the present study's measurement model. Partial Least Squares-Structural Equation Modeling (PLS-SEM) path modelling allows for estimating the hierarchical model and analysing complex path relationships between latent variables (Sarstedt, Henseler, \& Ringle, 2011). It is also useful for prediction accuracy and has been used more frequently than the covariance-based approach (Urbach \& Ahlemann, 2010). Non-parametric bootstrapping with 500 replications was applied to obtain the standard errors of the estimates. 


\section{Common method variance}

Common methods variance (CMV) can be a problem when dealing with latent variables and using a single source method. To address this problem, from the self-administered questionnaire, two kinds of Likert scales were employed: 5- and 6-point Likert scales. All these abovementioned methods were suggested by Hair, Black, Babin, and Anderson (2010) in order to reduce CMV in the data collection method. Furthermore, a pre-test, outliers, and multicollinearity checking (with cutoff 0.9 ) were also conducted prior to the main study. The findings suggest that CMV is not a major concern in this study.

\section{Assessment of the measurement model}

\section{Construct validity}

Construct validity of the instrument can be assessed by convergent and discriminant validity. The respective loadings and cross loadings were observed to look for outstanding items. The cutoff value for loadings was 0.40 (Henseler et al., 2009), thus the item with loading lower than 0.40 , in this case IJ4, was deleted. This was deemed acceptable as long as no more than $20 \%$ of the items of the whole measurement model were deleted (Hair et al., 2010). Consequently, the construct validity was confirmed when all of the items measuring a particular construct loaded highly on that construct, and lower on the other constructs.

\section{Convergent validity and reliability analysis}

According to Hair et al. (2010), convergent validity was assessed by using factor loadings, composite reliability (CR), and average variance extracted (AVE). Convergent validity was achieved when the multiple items measuring the same concept were in agreement. As shown in Table 1, the AVE for each construct exceeded the recommended value of 0.40 (Hulland, 1999), ranging from 0.60 to 0.66 , while the $\mathrm{CR}$ in our study ranged from 0.87 to 0.94 , exceeding the recommended value of 0.70 (Hair et. al., 2010). As such, we concluded that the measurements were reliable as the CR is interpreted similar to Cronbach's alpha for internal consistency reliability estimates. Bargaining (BG) and problem solving (PB) were indicated as single-item measures. The loadings were then indicated as 1.00, while the CR and AVE for each constructs were indicated as single item measures (SIM) respectively. 
Table 1

Results of measurement model

\begin{tabular}{|c|c|c|c|c|}
\hline Model construct & Item & Loadings & AVE & $\mathrm{CR}$ \\
\hline Bargaining & BG & 1.00 & SIM & SIM \\
\hline Problem solving & $\mathrm{PB}$ & 1.00 & SIM & SIM \\
\hline \multirow[t]{8}{*}{ Interactional justice } & $\mathrm{IJ} 1$ & 0.81 & 0.66 & 0.94 \\
\hline & $\mathrm{IJ} 2$ & 0.80 & & \\
\hline & IJ3 & 0.80 & & \\
\hline & IJ5 & 0.71 & & \\
\hline & IJ6 & 0.79 & & \\
\hline & IJ7 & 0.87 & & \\
\hline & IJ8 & 0.88 & & \\
\hline & IJ9 & 0.82 & & \\
\hline \multirow[t]{4}{*}{ Somatic strain } & SM1 & 0.80 & 0.64 & 0.87 \\
\hline & SM2 & 0.80 & & \\
\hline & SM3 & 0.84 & & \\
\hline & SM4 & 0.76 & & \\
\hline \multirow[t]{10}{*}{ Depressive symptom } & DP1 & 0.81 & 0.60 & 0.94 \\
\hline & DP2 & 0.81 & & \\
\hline & DP3 & 0.83 & & \\
\hline & DP4 & 0.85 & & \\
\hline & DP5 & 0.83 & & \\
\hline & DP6 & 0.76 & & \\
\hline & DP7 & 0.76 & & \\
\hline & DP8 & 0.85 & & \\
\hline & DP9 & 0.53 & & \\
\hline & DP10 & 0.62 & & \\
\hline
\end{tabular}

\section{Discriminant validity}

To ensure the discriminant validity of the model, the square root of the AVE should exceed the intercorrelations of the construct with the other constructs (Chin, 2010). Table 2 shows that all of the items loaded more strongly on their own constructs of the model, and the AVE shared between each construct and its measures are greater than the variance shared between the constructs and each construct. Thus, with sufficient reliability, convergent validity, and discriminant validity, the measurement model was considered satisfactory for hypotheses and the research model testing. As discussed in the literature review section, subscales for problem 
solving and bargaining styles were ranged between +4 and -4 . For the problem solving subscale, +4 represents a person's attempt to provide high concerns for both parties, whereas a -4 score represents a person's attempt to provide no or low concerns for both parties. Table 2 shows the mean score for problem solving is 0.605. This indicates respondents $(\mathrm{N}=390)$ are of average scoring 0.605 which is in the middle of the continuum of -4 and +4 subscale of problem solving. For the bargaining subscale, +4 indicates a person's attempt to provide high concern for self, while no or low concern for others. A -4 value indicates a person's attempt to provide no or low concern for self, and high by others. Because the mean score for bargaining styles is -0.928 , it indicates respondents $(\mathrm{N}=390)$ on average scored -0.928 , which is also in the middle of the continuum -4 and +4 on the bargaining subscale.

Table 2

Discriminant validity of constructs

\begin{tabular}{lrrrrrrr}
\hline Construct & M & SD & 1 & 2 & 3 & 4 & 5 \\
\hline Bargaining & -0.928 & 0.89 & SIM & & & & \\
Depressive symptom & 2.000 & 0.99 & 0.09 & $\mathbf{0 . 7 8}$ & & & \\
Interactional justice & 3.747 & 0.73 & -0.17 & -0.26 & $\mathbf{0 . 8 1}$ & & \\
Problem solving & 0.605 & 0.80 & -0.03 & -0.29 & 0.26 & SIM & \\
Somatic strain & 2.473 & 0.84 & 0.11 & 0.60 & -0.14 & -0.21 & $\mathbf{0 . 8 0}$ \\
\hline
\end{tabular}

Note: Square root of the AVE on the diagonal (in bold); $\mathrm{M}=$ mean; $\mathrm{SD}=$ standard deviation; $\mathrm{SIM}=$ single item measure

\section{RESULTS}

\section{Assessment of the Structural Model}

Table 3 presents the results of the path analysis with the hypotheses generated. The $\mathrm{R}^{2}$ value of somatic strain was 0.098 , suggesting that $9.80 \%$ of the variance in somatic strain could be explained by the conflict management styles. For depressive symptoms, the $\mathrm{R}^{2}$ value was 0.141 , indicating that $14.1 \%$ of the variance in depressive symptoms could be explained by conflict management styles.

A closer look shows a positive significant relationship from bargaining to somatic strain $(\beta=0.10, p=0.02)$. Two negative relationships were found between problem solving and somatic strain $(\beta=-0.22, p<0.001)$, and between problem solving and depressive symptoms $(\beta=-0.17, p<0.001)$. Therefore, H1, H3, and H4 were supported. For H2, no significant relationship was found between bargaining and depressive symptoms. 
Table 3

Path coefficients and hypotheses testing

\begin{tabular}{clcccc}
\hline Hypothesis & Construct & Beta & SE & $t$-value & Supported \\
\hline H1 & BG $\rightarrow$ SM & 0.10 & 0.05 & $1.98^{*}$ & Yes \\
H2 & BG $\rightarrow$ DS & 0.06 & 0.04 & 1.25 & No \\
H3 & PB $\rightarrow$ SM & -0.22 & 0.05 & $4.79^{* *}$ & Yes \\
H4 & PB $\rightarrow$ DS & -0.17 & 0.05 & $3.17^{* *}$ & Yes \\
H5 & BG * IJ $\rightarrow$ SM & -0.15 & 0.06 & $2.50^{* *}$ & Yes \\
H6 & BG * IJ $\rightarrow$ DS & -0.11 & 0.06 & $1.81^{*}$ & Yes \\
\hline
\end{tabular}

Note: $\mathrm{SE}=$ standard error; $\mathrm{BG}=$ bargaining; $\mathrm{DS}=$ depressive symptoms; $\mathrm{IJ}=$ interactional justice; $\mathrm{PB}=$ problem solving; $\mathrm{SM}=$ somatic strain

${ }^{* *} p<0.01 ;{ }^{*} p<0.05$

\section{Moderating Effect}

To apply the moderating analysis, the PLS-SEM product-indicator approach was used to detect the moderating effect of perceived interactional justice on the relationship between bargaining style and somatic strain (H5). As shown in Figure 2, the interaction between bargaining and interactional justice was significant. When interactional justice was high, bargaining was significantly and negatively related to somatic strain indicating a negative relationship between bargaining and somatic strain $(B=-0.15, p=0.006)$. Furthermore, bargaining and somatic strain were positively related when interactional justice was low, confirming the moderation effect of interactional justice on somatic strain. As an alternative way to explain our findings, subordinates who used bargaining experienced lower somatic strain when they perceived high interactional justice from their supervisors rather than when the perceived interactional justice was low. Thus, H5 was supported.

For H6, the moderation effect of interactional justice on the relationship between bargaining and depression symptoms was also confirmed. With a more detailed look of Figure 3, there is a significant positive relationship between bargaining and depressive symptoms when interactional justice was low $(B=-0.11$, $p=0.03$ ). When interactional justice was high, bargaining was negatively related with depressive symptoms. In other words, subordinates who used bargaining experienced lower depressive symptoms when perceived interactional justice was high rather than when perceived interactional justice was low.

The effect size of the interactional justice moderating effect on somatic strain is 0.031 , while the effect size of the interactional justice moderating effect on 
depressive symptoms is 0.014 . Both indicated small to medium effects on somatic strain and depressive symptoms, respectively (Hair et al., 2010). The predictive relevance of somatic strain is 0.060 , while depressive symptoms is 0.062 indicating medium to large predictive relevance (Henseler et al., 2009).

Although not hypothesised, the moderation effect of interactional justice on the relationships between problem solving and psychological strains was analysed. Results showed no significant moderation effect on this relationship.

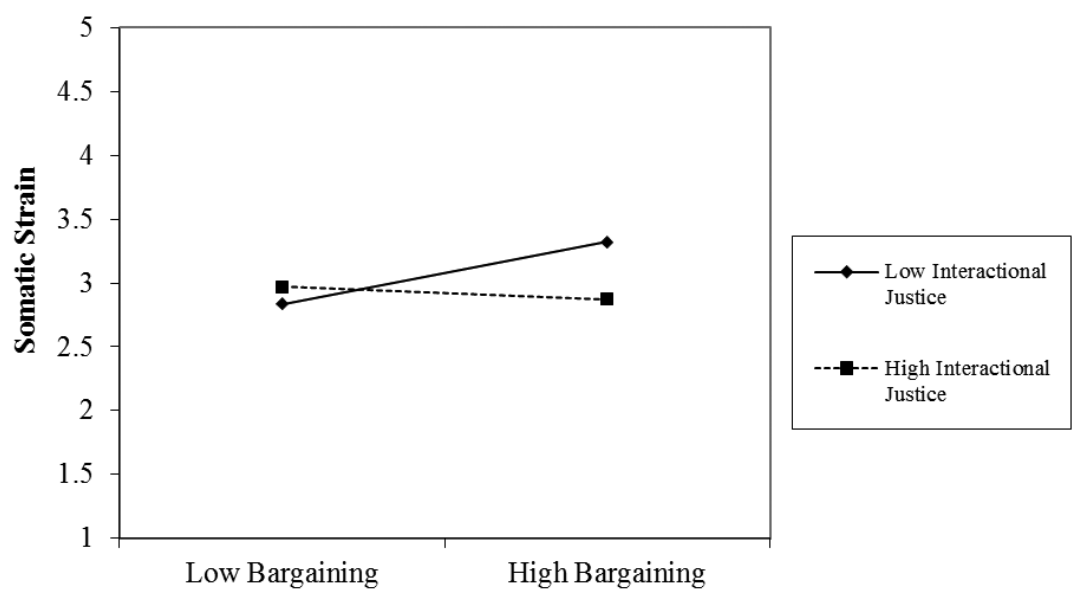

Figure 2. Moderating effects of interactional justice on the relationship between bargaining and somatic strain.

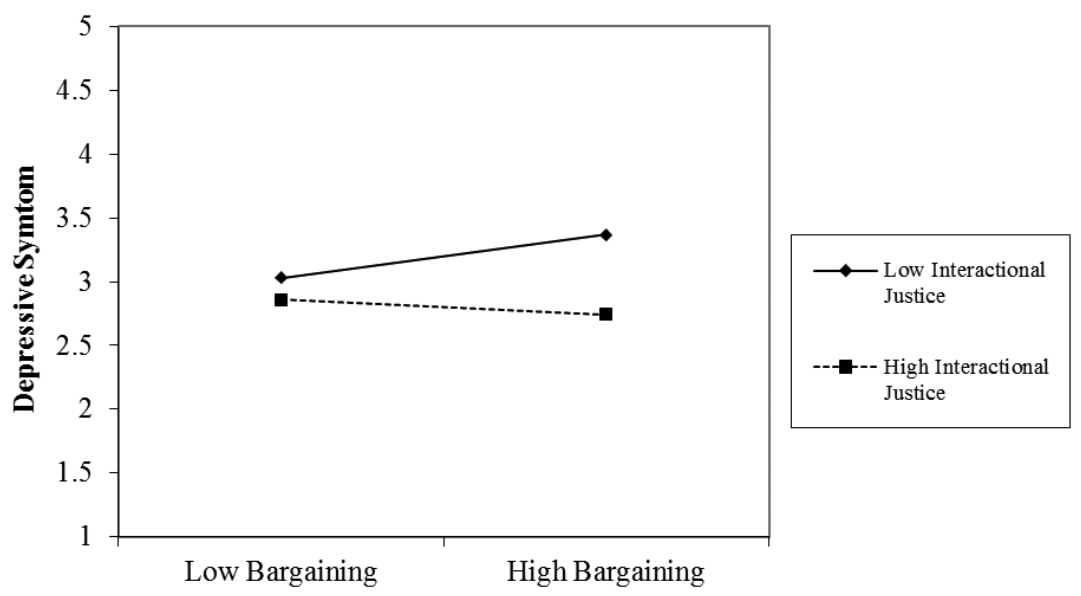

Figure 3. Moderating effects of interactional justice on the relationship between bargaining and depressive symptom. 


\section{DISCUSSION}

The aim of this paper is twofold. First, this paper investigated the relationships between conflict management styles: bargaining and problem solving on subordinates' psychological strain operationalised by somatic strain and depressive symptoms. In particular and consistent with the Dual Concern Model (Blake \& Mouton, 1964; Rahim, 2010), it was found that bargaining was positively related to somatic strain, supporting that subordinates who are concerned with one's own or with other's interests and used win-lose strategy experienced high somatic strain. By neglecting one's parties' interests in managing conflicts, their strain may increase due to the accumulated experience of negative affects derived from the hostile attitudes and behaviours.

However, depressive symptoms were not significantly related to their use of bargaining styles. Presumably this was because depressive symptoms are caused by multiple factors (e.g., critical life events, job insecurity) of which an inadequate conflict management style is only one. On the contrary, subordinates who used problem solving styles when having interpersonal conflicts with their supervisors were demonstrated to have lower somatic strain and fewer depressive symptoms than their counterparts. Supported by previous research (e.g., Rahim, 2010), subordinates who were prosocial oriented and who have high concern for self and others were less exposed to the environment with less conflict, which in turn lessens work stressors.

The second aim of the study proposed that perceived interactional justice moderated the positive relationships of bargaining style on somatic strain and depressive symptoms. As hypothesised, the findings revealed perceived interactional justice of supervisors buffered the negative consequences of the use of bargaining styles on subordinates' somatic strain and depressive symptoms. This means that supervisors who provide higher interactional justice can help their subordinates who prefer bargaining styles in managing conflicts to be less vulnerable to negative consequences of work stressors when the supervisors perform respectful treatment with a high level of dignity, and provide detailed feedback and procedure in a timely manner towards these subordinates (e.g., Colquitt, 2001; Judge \& Colquitt, 2004). Furthermore, their somatic strain and depressive symptoms are also decreased because of the positive healthy working environment that is built based on the reciprocal relationship. Thus, it complies to the requirement of having positive social interactions deriving reciprocal relationships with supervisors in agreement with SET (Blau, 1964). In regards to depressive symptoms, our results support the previous empirical literature on social support, in particular good supervisory support and managerial skills (Kawakami et al., 2005; Kuoppala, Lamminpää, 
Liira, \& Vainio, 2008). Therefore, it is confirmed that this study was successful in achieving its objectives, particularly due to the effect of interactional justice as the "helping hand."

\section{CONCLUSION}

\section{Theoretical and Practical Implications}

The current findings add to a growing body of conflict and justice literature in a number of ways. From a theoretical point, the "soft" outcomes of conflicts, i.e., the psychological strain, are studied comprehensively using the bargaining and problem solving styles with the conflict management styles. Furthermore, because the problem solving style successfully shown in this study has the advantageous in high concerns for both parties and social value orientation (dispositional), and positive work environment (situational) (De Dreu, van Dierendonck, \& Dijkstra, 2004), these findings also contribute to the studies of personality theories in managing conflicts in a way that disposition can be one of the determinants in conflict management styles.

Another implication of our findings made contributions in the way of the employing informational justice construct. In their ten-year review on organisational justice and mental health, Ndjaboué, Brisson, and Vézina (2012) found that the lack of studies on the informational justice facet caused a missing link in the presence, or absence, of explanations from the supervisory authority in delivering information. The use of this facet in our research followed the suggestion to complete the assessment of organisational justice research by adding the informational justice facet to the literature.

The practical implications of our findings, with respect to achieving long-term effects, suggest a more productive approach. First, justice and fairness training for supervisors should be organised to make them more aware about their subordinates' values and preferences in conflict situations. The ultimate goal is to enable employees in power (supervisors) to be aware of, and sensitive to, those with less power and different points of view (subordinates), and consequently enable the subordinates to voice their views when conflicts occur. This is particularly important for a high power distance culture, such as Malaysia, which values a hierarchy where the individuals are willing to accept/expect power to be distributed unequally (Hofstede, 2001). With levels of perceived interactional justice acceptably high, supervisors should seek to strengthen the relationships between conflict management styles and well-being. A deeper grasp of interactional 
justice will assist both the supervisors and subordinates in better understanding and respecting each other's behaviour in order to produce a more positive social climate at work.

Second, the styles which the subordinates preferred were shown to have pervasive consequences on their work life. As mentioned above, those who are more integrated in reaching decisions showed lower psychological strain at work, while those who preferred to bargain demonstrate higher psychological strain than their counterparts. Since both dispositional and situational factors determine the styles in managing conflicts, subordinates could be encouraged to remedy their conflict management styles in order to enhance their well-being (Haraway \& Haraway III, 2005). Awareness of this mutual-gains negotiation may assist them in learning to act in ways that improve their health. Finally, this gathered information can be used for both supervisors and their subordinates in their organisations' assistance programmes to combat workplace strain and maintain the work relationships and harmony. Supervisor-subordinate involvement in the decision-making process could reduce threats related to potentially sensitive conflict-triggers in the workplace which could subsequently affect their well-being.

\section{Limitations and Directions for Future Research}

The current results reveal several limitations. First, our study relied upon selfreport measures, which creates the potential for common method variance. However, as mentioned previously, to address this issue, well-developed theories were utilised to guide the study, relying on valid and reliable data and measures, using a method that is consistent with the purpose of the study, and implementing appropriate strategies in data analysis (Hair et al., 2010). Yet, it is encouraged that future research could assess relevant physiological data (e.g., cortisol levels) and conflict management styles scores that were obtained from dyad sources (e.g., both self and supervisors).

As with all cross-sectional research designs, this study cannot definitively state the causal direction of the hypotheses. Hence, replications with prospective measures with other kinds of organisations (public vs. private), cultures (collectivism vs. individualism) are still needed to assess the causality and generalisability of the association between conflict management styles and subordinates' well-being. Moreover, in terms of generalisability of the findings, we cannot rule out the possibility that subordinates who were not experiencing ongoing conflicts with their supervisors, and subordinates that were healthy physically and mentally, were the only ones willing to participate in the study. This could have led to an underestimation of the true relations. 
A final issue warranting discussion is that depending on the situation, a combination of different styles derived from different set of theories may be more advantageous in making decisions and resolving conflicts. According to a Situational Leadership Theory (Hersey \& Blanchard, 1969), a supervisor needs to employ a directing approach, requires a more of dominating style for subordinates who are not able and willing to perform tasks. On the other hand, the same supervisor needs to use a more of compromising and integrating styles for employees who are both able and willing to perform tasks.

It also acknowledged that the intensity and dynamic of conflicts acquire different uses of conflict management styles which build upon the phase of such conflicts. For example, obliging, avoiding, and dominating styles, may be appropriate to use when faced with daily and minor problems in organisations, rather than integrating, which may be more an appropriate style to use with complex problems (Rahim, 2010). Therefore, future studies may consider stating specific problems or situations in which managing supervisory conflicts interactional justice is needed as a helping hand.

\section{NOTE}

1. Rahim Organizational Conflict Inventory-II, Form A - used with permission from the Center for Advanced Studies in Management. Further use or reproduction of the instrument without written permission is prohibited.

\section{REFERENCES}

Abas, N.A.H., Otto, K., \& Thurasamy, R. (2015). The relationship between depressive symptoms and job satisfaction in a collectivistic culture: The moderating role of cultural embeddedness. Jurnal Psikologi Malaysia, 29(1), 1-20.

Bech, P., Rasmussen, N.A., Olsen, L.R., Noerholm, V., \& Abildgaard, W. (2001). The sensitivity and specificity of the major depression inventory, using the present state examination as the index of diagnostic validity. Journal of Affective Disorders, 66(2-3), 159-164. https://doi.org/10.1016/S0165-0327(00)00309-8

Blake, R.R., \& Mouton, J.S. (1964). The managerial grid. Houston, TX: Gulf Publishing. Blau, P.M. (1964). Exchange and power in social life. New York, NY: John Wiley.

Bono, G., McCullough, M.E, \& Root, L.M. (2008). Forgiveness, feeling connected to others, and well-being: Two longitudinal studies. Personality and Social Psychology Bulletin, 34(2), 182-195. https://doi.org/10.1177/0146167207310025 
Bruk-Lee, V., \& Spector, P. (2006). The social stressors-counterproductive work behaviors link: Are conflicts with supervisors and coworkers the same? Journal of Occupational Health Psychology, 11, 145-156. https://doi.org/10.1037/10768998.11.2.145

Claire, L.S. (2016). Rival truths: Common sense and social psychological explanations in health and illness (reprint). UK: Psychology Press Ltd.

Chin, W.W. (2010). How to write up and report PLS analyses. In V. Esposito Vinzi, W.W. Chin, J. Henseler, \& H. Wang (Eds.), Handbook of partial least squares: Concepts, methods and applications in marketing and related fields (pp. 655690). Berlin: Springer. https://doi.org/10.1007/978-3-540-32827-8_29

Cohen-Charash, Y., \& Spector, P.E. (2001). The role of justice in organizations: A metaanalysis. Organizational Behavior and Human Decision Processes, 86(2), 278321. https://doi.org/10.1006/obhd.2001.2958

Colquitt, J.A. (2001). On the dimensionality of organizational justice: A construct validation of a measure. Journal of Applied Psychology, 86(3), 386-400. https:// doi.org/10.1037/0021-9010.86.3.386

Cropanzano, R., Prehar, C.A., \& Chen, P.Y. (2002). Using social exchange theory to distinguish procedural from interactional justice. Group and Organization Management, 27(3), 324-351. https://doi.org/10.1177/1059601102027003002

De Dreu, C.K.W., \& Beersma, B. (2005). Conflict in organizations: Beyond effectiveness and performance. European Journal of Work and Organizational Psychology, 14(2), 105-117. https://doi.org/10.1080/13594320444000227

De Dreu, C.K.W., van Dierendonck, D., \& Dijkstra, M.T.M. (2004). Conflict at work and individual well-being. The International Journal of Conflict Management, 15(1), 6-26. https://doi.org/10.1108/eb022905

De Dreu, C.K.W., \& Van Lange, P.A. (1995). The impact of social value orientations on negotiator cognition and behavior. Personality and Social Psychology Bulletin, 21(11), 1178-1188. https://doi.org/10.1177/01461672952111006

Elovainio, M., Kivimäki, M., \& Vahtera, J. (2002). Organizational justice: Evidence of a new psychosocial predictor of health. American Journal of Public Health, 92(1), 105-108. https://doi.org/10.2105/AJPH.92.1.105

Friedman, R.A., Tidd, S.T., Currall, S.C., \& Tsai, J.C. (2000). What goes around comes around: The impact of personal conflict style on work group conflict and stress. International Journal of Conflict Management, 11(1), 32-35. https://doi. org/10.1108/eb022834

Frone, M.R. (2000). Interpersonal conflict at work and psychological outcomes: Testing a model among young workers. Journal of Occupational Health Psychology, 5(2), 246-255. https://doi.org/10.1037/1076-8998.5.2.246

Hair, J.F., Black, W.C., Babin, B.J., \& Anderson R.E. (2010). Multivariate data analysis. New Jersey: Prentice-Hall.

Haraway, D.L., \& Haraway III, W.M. (2005). Analysis of the effect of conflict management and resolution training on employee stress at a healthcare organization. Hospital Topics: Research and Perspectives on Health Care, 83(4), 11-17. https://doi. org/10.3200/HTPS.83.4.11-18 
Henseler, J., Ringle, C.M., \& Sinkovics, R.R. (2009). The use of partial least squares path modeling in international marketing. Advances in International Marketing, 20, 277-320. https://doi.org/10.1108/S1474-7979(2009)0000020014

Hersey, P., \& Blanchard, K.H. (1969). Management of organizational behavior: Utilizing human resources. New Jersey: Prentice-Hall.

Hofstede, G. (2001). Culture's consequences: Comparing values, behaviors, institutions, and organizations across nations (2nd ed.). Thousand Oaks, CA: Sage Publications.

Hulland, J.S. (1999). Use of partial least squares (PLS) in strategic management research: A review of four recent studies. Strategic Management Journal, 20(4), 195-204. https://doi.org/10.1002/(SICI)1097-0266(199902)20:2\%3C195::AIDSMJ13\%3E3.0.CO;2-7

Judge, T.A., \& Colquitt, J.A. (2004). Organizational justice and stress: The mediating role of work-family conflict. Journal of Applied Psychology, 89(3), 395-404. https:// doi.org/10.1037/0021-9010.89.3.395

Kawakami, N., Kobayashi, Y., Takao, S., \& Tsutsumi, A. (2005). Effects of web-based supervisor training on supervisor support and psychological distress among workers: A randomised controlled trial. Prevention Medicine, 41(2), 471-478. https://doi.org/10.1016/j.ypmed.2005.01.001

Kuoppala, J., Lamminpää, A., Liira, J., \& Vainio, H. (2008). Leadership, job wellbeing, and health effects: A systematic review and a meta-analysis. Journal of Occupational and Environmental Medicine, 50(8), 904-915. https://doi. org/10.1097/JOM.0b013e31817e918d

McGorry, S.Y. (2000). Measurement in a cross-cultural environment: Survey translation issues. Qualitative Market Research: An International Journal, 3(2), 74-81. https://doi.org/10.1108/13522750010322070

Meier, L.L., Semmer, N.K., \& Gross, S. (2014). The effect of conflict at work on wellbeing: Depressive symptoms as a vulnerability factor. Work \& Stress, 28(1), 3148. https://doi.org/10.1080/02678373.2013.876691

Ndjaboué, R., Brisson, C., \& Vézina M. (2012). Organisational justice and mental health: A systematic review of prospective studies. Occupational \& Environmental Medicine, 69(10), 694-700. https://doi.org/10.1136/oemed-2011-100595

Patient, D.L., \& Skarlicki, D.P. (2010). Increasing interpersonal and informational justice when communicating negative news: The role of the manager's empathic concern and moral development. Journal of Management, 36(2), 555-578. https://doi. org $/ 10.1177 / 0149206308328509$

Pejtersen, J.H., Søndergård Kristensen, T., Borg, V., \& Bjorner, J.B. (2010). The second version of the Copenhagen psychosocial questionnaire. Scandinavian Journal of Public Health, 38(3), 8-24. https://doi.org/10.1177/1403494809349858

Quiñones, V., Jurska, J., Fener, E., \& Miranda, R. (2015). Active and passive problem solving: Moderating role in the relation between depressive symptoms and future suicidal ideation varies by suicide attempt history. Journal Clinical Psychology, 71(4), 402-412. https://doi.org/10.1002/jclp.22155

Rahim, M.A. (2010). Managing conflicts in organization (4th ed.). New Brunswick, NJ: Transaction Publishers. 
Rahim, M.A., Antonioni, D., \& Psenicka, C. (2001). A structural equations model of leader power, subordinates' styles of handling conflict, and job performance. International Journal of Conflict Management, 12(3), 191-211. https://doi. org/10.1108/eb022855

Rahim, M.A., \& Bonoma, T.V. (1979). Managing organizational conflict: A model for diagnosis and intervention. Psychological Reports, 44(3c), 1323-1344. https://doi.org/10.2466/pr0.1979.44.3c.1323

Ringle, C.M., Wende, S., \& Will, A. (2005). SmartPLS 2.0 (Beta). Retrieved 25 February 2014 from www.smartpls.de.

Sarstedt, M., Henseler, J., \& Ringle, C.M. (2011). Multi-group analysis in Partial Least Squares (PLS) path modeling: Alternative methods and empirical results. Advances in International Marketing, 22(1), 195-218. https://oi.org/10.1108/ S1474-7979(2011)0000022012

Schutz, W.C. (2015). The social psychology of groups by J.W. Thibaut and H.H. Kelley. International Journal of Group Psychotherapy, 11(3), 353-354. https://doi.org/1 0.1080/00207284.1961.11508188

Spector, P.E., \& Bruk-Lee, V. (2008). Conflict, health, and well-being. In C.K.W. De Dreu \& M.J. Gelfand (Eds.), The psychology of conflict and conflict management in organizations (pp. 267-288). San Francisco, CA: Jossey-Bass.

Urbach, N., \& Ahlemann, F. (2010). Structural equation modeling in information systems research using the partial least squares approach. Journal of Information Technology Theory and Application, 11(2), 5-40.

Walton, R.E., \& McKersie, R.B. (1965). A behavioral theory of labor negotiations: An analysis of a social interaction system. New York, NY: McGraw-Hill. 